has progressively increased in income group A until it crossed the descending line of carbohydrate calories in 1969.

The official silence about diet and heart disease that has prevailed in this country has now been broken. The implications of the panel's recommendations for the food industry, for government food regulations and subsidies, and even for the E.E.C. agricultural arrangements will need to be carefully studied. Sweden followed up the 1968 Scandinavian recommendations ${ }^{8}$ by a diet and exercise campaign, and the Swedish fat intake has fallen from 42 to $40 \%$ of the total energy in the diet. Nevertheless, the report is not one of the tablets of stone brought down the mountain by Moses, and the official British recommendations on this important subject will need to be reconsidered at regular intervals-as is being done in the U.S.A. and Australia.

\footnotetext{
${ }^{1}$ Inter-Society Commission for Heart Disease Resources, Circulation, 1970, 42, A-55.

American Medical Association Council on Foods and Nutrition, fournal of the American Medical Association, 1972, 222, 1647

3 Committee on Food and Nutrition, American Health Foundation Preventive Medicine, 1972, 1, 255.

Mayer, J., in U.S. Nutrition Policies in the Seventies, p. 44. San Francisco, Freeman, 1973.

American Heart Association, Diet and Heart Disease, 1973.

${ }^{6}$ Report of a Committee of the Royal Society of New Zealand, Coronary Heart Disease. New Zealand, Royal Society, 1971.

7 National Heart Foundation of New Zealand. Coronary Heart Disease.

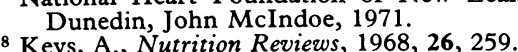

${ }^{8}$ Keys, A., Nutrition Reviews, $1968,26,259$. 1974, 1, 575.

10 Voedingsraad, Advies over Hoeveelheid en/of Aard der Vetten in de Voeding. Staatsuitgeverij, Holland, s'Gravenhage, 1973.

11 Council on Rehabilitation, International Society of Cardiology, Myocardial Infarction. How to Prevent, How to Rehabilitate, 1973.

12 Department of Health and Social Security, Diet and Coronary Heart Disease, Health and Social Subjects 7. London, H.M.S.O., 1974.

13 Morris, J. N., et al., Lancet, 1966, 2, 553.

14 Kannel, W. B., et al., Circulation, 1967, 35, 734.

15 Montenegro, M. R., and Solberg, L. A., Laboratory Investigation, 1968,

18, 594.
16 Keys, A., et al., Annals of Internal Medicine, 1972, 77, 15.

17 Evans, D. W., Turner, S. M., and Ghosh, P., Lancet, 1972, 1, 172.

18 Shaper, A. G., and Marr, J. W., in Lipid Metabolism and Atherosclerosis, ed. D. W. K. Cotton, p. 43. Amsterdam, Excerpta Medica, 1973.

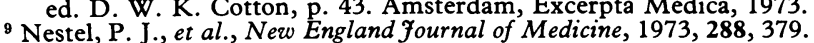

19 Nestel, P. J., et al., New England Fournal of Medicine, 1973, 288, 379 . Food Additives. World Health Organization Technical Report Series No. 488, p. 36. Geneva, W.H.O., 1972.

1 Joosens, J. V., Triangle, 1973, 12, 9.

22 Marr, J. W., and Berry, W. T. C., Nutrition, 1974, 28, 39.
}

\section{Aspirin and What Else?}

Two thousand tons of aspirin are swallowed in Britain every year, which works out theoretically at about two tablets for every inhabitant per week. A small survey found that $23 \%$ of men and $52 \%$ of females attending a general practitioner's surgery took ten or more aspirin tablets in a single month. ${ }^{1}$ Yet aspirin remains one of the safest drugs, and this in spite of its many pharmacological effects and its influences on so many basic mechanisms, on all of which it probably acts by inhibiting prostaglandin synthesis. ${ }^{2}$

There is no doubt that aspirin prolongs the bleeding time in normal people to a small but technically significant extent, ${ }^{3}$ and it seems reasonable to attribute this effect to an alteration in platelet function. After platelets have stuck to a surface or to each other, adenosine diphosphate (ADP) and other substances are released. ${ }^{4}$ This released ADP then causes other platelets to become sticky, and thus haemostasis is achieved by progressively building up platelet plugs in the small vessels. Aspirin prevents the release reaction, ${ }^{5-8}$ and this is almost certainly why the bleeding time of normal people is marginally prolonged.
The regular but trivial increase in blood loss from the alimentary tract after aspirin ingestion ${ }^{9}$ is probably due to the same effect on platelets. But why does a very occasional person have profuse gastric haemorrhage after taking aspirin ? Among the hundreds of thousands of people eating aspirin, why do a very few have this idiosyncratic response? In the light of recent work it is possible to hazard an outline of an answer to this question of such great clinical importance.

It is a pharmacological truism that the effect of giving two drugs affecting exactly the same pathway will be additive, but if they influence related but different pathways the effect will be far greater-potentiation. This law applies when aspirin is given when other haemostatic defects are known to exist. For example, most of the time patients with von Willebrand's disease or with haemophilia do not bleed though they are at risk. If they are given aspirin the chance of haemorrhage is greatly increased; furthermore the bleeding time is greatly and disproportionately prolonged by aspirin in von Willebrand's disease $\mathrm{e}^{10}$; this abnormality is potentiated. Similarly, in a third and completely different upset of haemostasis, that induced by warfarin, aspirin again considerably increases the chance of bleeding. There is scant evidence that aspirin has a hypoprothrombinaemic effect, ${ }^{11}$ but it almost certainly increases the chance of bleeding through its effects on platelets. Indeed anticoagulants alone have no effect on the bleeding time, and aspirin alone has a slight effect; but together they cause considerable prolongation ${ }^{11}$ - a clear case of potentiation. Alcohol, unless it causes cirrhosis, does not effect haemostasis, but it causes acute gastritis. Again, with a local lesion such as alcoholic gastritis ${ }^{12}$ or with a peptic ulcer it is unwise to take aspirin as the risk of haemorrhage is increased.

This argument can be extended logically to include the suggestion that those who bleed profusely after aspirin probably do not have a strictly normal haemostatic mechanism before this second haemostatic insult is superimposed. In any clinic dealing with haemostatic defects many patients present with stories of bleeding outside the ordinary experience, yet no gross obvious abnormality is revealed by the relatively crude and insensitive clinical platelet function tests available. Alternatively a clinically mild platelet defect such as thrombopathia (storage pool deficiency ${ }^{13}$ ) may be demonstrated; relatives may be shown to have the same platelet function defect, yet they may have no evidence of bleeding. The suggestion is that it is these potential bleeders with mild or silent defects who are at risk after taking aspirin.

A recent study ${ }^{14}$ lends some support to this suggestion. Eleven patients with gross gastrointestinal haemorrhage after taking aspirin were studied at least eight (mean 10) days later. Another 11 patients had bled but had not taken aspirin; these two groups were compared with each other and 11 controls who had neither bled nor taken aspirin. The results are difficult to interpret, since the platelets studied soon after acute haemorrhage are almost certainly young and may be more active, ${ }^{15}$ but there was some evidence that the release mechanism stimulated by collagen was more completely inhibited by adding aspirin in the post-aspirin bleeding group than in the others. This may indicate a metabolic difference in the way these patients handle aspirin. Perhaps more relevant is the hint of malfunction, namely poor release, in three of the nonaspirin bleeders. Larger numbers of patients in all these three categories need to be extensively studied after they have completely recovered from the aspirin and from the effect of haemorrhage to confirm these findings.

It should probably be accepted that in the presence of a history of even slightly prolonged bleeding after tooth extrac- 
tion or of other evidence possibly suggesting a mild haemostatic defect, use of aspirin (and other anti-inflammatory drugs including meclofenamic acid, indomethacin, ibuprofen, and mefenamic acid ${ }^{\mathbf{1 6}}$ ) should be discouraged. Paracetamol has no effect on platelets in vitro and probably can be substituted with reasonable safety. For a more powerful analgesic effect dihydrocodeine bitartrate can be recommended.

1 O'Brien, J. R., Lancet, 1970, 1, 1055.

2 Vane, J. R., Hospital Practice, 1972, 7, 61.

3 Mielke, C. H., et al., Blood, 1969, 34, 207

4 Holmsen, H., Day, H. J., and Stormorken, H., Scandinavian Fournal of Haematology, 1969, Supplement 8.

5 Weiss, H. J., Aldedort, L. M., and Kochwa, S., fournal of Clinical Investigation, 1968, 47, 2169.

Cucker, M. B., and Peterson, J., Proceedings of the Society for Experimental Biology and Medicine, 1968, 127, 547 .

' O'Brien, J. R., Lancet, 1968, 1, 779.

8 Evans, G., Packham, M. A., and Nishizawa, E. E., fournal of Experimental Medicine, 1968, 128, 877

Gróssman, M. I., Matsumoto, K. K., and Lichter, R. J., Gastroenterology, $1961,40,383$.

10 Quick, A. J., American Fournal of Medical Science, 1966, 252, 45, 265

11 O'Reilly, R. A., Sahud, M. A., and Aggeler, P. M., Annals of the New York Academy of Sciences, 1971, 179, 173.

Academy of Sciences, 1971, 179, 173.
12 Needham, C. D., et al., Gut, 1971, 12, 819.

12 Needham, C. D., et al., Gut, 1971, 12, 819. 187.

13 Weiss, H. J., and Rogers, J., Blood, 1972, 39, 187.

14 Mills, D. G., et al., Clinical Pharmacology and Therapeutics,

16 O'Brien, I. R., Lancet, 1968, 1, 894.

\section{Inflation and the B.M.A.}

Planning the budget of a democratic, voluntary body like the B.M.A. is hard enough in "normal" times. To do so in these inflationary days is like playing Monopoly on a board composed almost entirely of penalty squares. When the Council approved its annual report in April and asked for a 1975 subscription of $£ 30$ it thought that if "all went well" the Association would just about break even next year. By the time the Treasurer rises to present the Financial Report at the A.R.M. on 12 July the B.M.A.'s estimated budgetary deficit for 1975 -assuming a $£ 30$ subscription-will almost certainly be well into six figures. Sloppy budgeting, critical members might say-but this would be unfair comment, for the 1975 budget was most carefully prepared with $12.5 \%$ inflation allowed for and all expenditure pruned as much as possible without lowering the standard of service to members.

This gloomy financial picture is the inevitable consequence of savage inflation, which hits a labour-intensive service organization like the B.M.A. particularly hard. It has suffered the double blow of rising costs and statutory limitation of its substantial rental income. The Council's Annual Report puts the potential loss from the latter at $£ 100,000$ and last month the Government proposed further legislation which could limit increases in business rents. The B.M.A.'s income from its investments and formidable capital assets in Bloomsbury and elsewhere, the result of sound husbandry in the past, has enabled successive A.R.M.'s to keep the Association's subscription at a reasonable level, and these legal restraints on income are a serious handicap when costs are not similarly controlled. Indeed, though the present rise may seem high in percentage terms, the subscription will have been at $£ 21$ for three years and in a difficult period Dr. S. Wand and his successor as Treasurer, Dr. J. E. Miller, have managed broadly to balance expenditure and income. A subscription of $£ 30$ stands comparison with that of other professional organizations in the U.K., and few of these have most of their members working in a state monopoly with the massive negotiating commitments that implies. In fact, taking the subscription ladder into account the average B.M.A. subscription in 1975 is only $£ 19$, and most members can set this against their tax. Nevertheless, any increase will prompt many doctors-particularly those in the N.H.S. who contribute to their defence trusts-to look at their subscription priorities. Without the irresistible attractions of the G.M.C. or the medical defence bodies the B.M.A. must somehow attract members strictly on its merits.

So with even $£ 30$ seemingly insufficient to fund the present level of activities in 1975 what action is the B.M.A. to take? It can raise the subscription further, cut expenditure, look for other sources of income, or juggle with a combination of these possibilities. Before deciding, however, the Representative Body will wish to balance most carefully the risk of losing members by pushing the subscription out of their reach against the hazard that by cutting services fewer doctors will find what they want in the B.M.A. Activities in traditional institutions like the B.M.A. rarely grow in a planned or logical fashion. This has allowed the B.M.A. to provide for the catholicity of tastes that makes medicine such a great and fascinating profession. But, sadly, such growth does not always lend itself to efficiency and if a representative organization is to function at all well in a complex and inflationbeleagured society then it must pay more than lip service to cost-effectiveness.

There is a limit, however, to what can be achieved by redeployment of staff or economizing on accommodation at Tavistock Square. With the threatened deficit more drastic solutions may be needed. Outright cuts in services have a certain surgical appeal. Some might suggest, for instance, stopping overseas meetings, withdrawing from the W.M.A. and C.M.A., dispensing with the Association's scientific work, or reducing the number of regional offices. Such an approach could save substantial sums but other doctors may well think these activities worth paying for.

But cuts are not always the best road to solvency. Perhaps the B.M.A. might link with other medical organizations in running certain common facilities like professional lists and document distribution. Would members welcome the B.M.A.'s undertaking medical defence services for them ? Doctors often complain that the Association is remote. Would the introduction of paid part-time local officials, as discussed by Dr. R. A. A. R. Lawrence in the Supplement this week (p. 55), generate more local interest and, therefore, a higher membership ? The B.M.A.'s income would be boosted to a more comfortable level by a healthy rise in the proportion of the profession who belong-at present around $65 \%$. Other solutions may occur to members and it is certainly important that the matter should be thrashed out in public. But the plain truth is that B.M.A. members get for half the present-day annual subscription to a golf club the services of a highly active trade union in all branches of medicine, personal help with superannuation or finding jobs, a local social and political society, scientific activities, and a large library-and a free B.M.F. every week. It is remarkable, really, that such a service has been provided so cheaply for so long. 